\title{
“No meu quintal, não!”. Contributos para uma análise dos movimentos ambientais de raiz popular em Portugal (1974-1994)
}

"Not in my backyard!". Contributions Towards an Analysis of Grassroots Environmental Movements in Portugal (1974-1994)

«Pas dans mon jardin!». Contributions à une analyse des mouvements de la défense de l'environnement d'origine populaire au Portugal (1974-1994)

\section{Elisabete Figueiredo e Teresa Fidélis}

\section{OpenEdition}

\section{Journals}

Edição electrónica

URL: http://journals.openedition.org/rccs/1187

DOI: $10.4000 /$ rccs. 1187

ISSN: $2182-7435$

\section{Editora}

Centro de Estudos Sociais da Universidade de Coimbra

Edição impressa

Data de publição: 1 Maio 2003

Paginação: 151-173

ISSN: 0254-1106

Refêrencia eletrónica

Elisabete Figueiredo e Teresa Fidélis, « "No meu quintal, não!". Contributos para uma análise dos movimentos ambientais de raiz popular em Portugal (1974-1994) », Revista Crítica de Ciências Sociais [Online], 65 | 2003, colocado online no dia 01 outubro 2012, criado a 04 maio 2019. URL : http:// journals.openedition.org/rccs/1187 ; DOI : 10.4000/rccs. 1187 


\title{
ELISABETE FIGUEIREDO TERESA FIDÉLIS
}

\section{“No meu quintal, não!". Contributos para uma análise dos movimentos ambientais de raiz popular em Portugal (1974-1994) '}

\begin{abstract}
Este trabalho tem por objectivo principal fornecer uma visão genérica sobre a acção ambientalista de raiz popular em Portugal entre os anos de 1974 e 1994, tendo em conta os principais contornos de movimentos de base popular, bem como a sua articulação com as características mais globais da sociedade portuguesa relativamente às questões ambientais e a sua relação com o contexto social, político e económico do país ao longo das duas décadas consideradas. No decorrer destas décadas, os movimentos ambientais de raiz popular, ainda que possam ser entendidos como resultado directo das alterações verificadas no nosso país, caracterizam-se essencialmente como Nimby - "no meu quintal, não!" -, como é particularmente evidenciado pelo âmbito geográfico e temporal restrito das acções de protesto levadas a cabo, pela ênfase na defesa de interesses privados e/ou locais e ainda pela não continuidade das acções ou pela ausência do alargamento a causas ambientais de natureza mais abrangente.
\end{abstract}

\section{Introdução}

Nos últimos anos, tem crescido o reconhecimento de que as questões ambientais são sentidas como questões sociais, quer no chamado mundo desenvolvido quer em países em vias de desenvolvimento. Isto torna-se particularmente evidente se forem tidas em conta as relações estreitas entre as preocupações com o ambiente e questões como a saúde, os impactes socioeconómicos e a propriedade privada (Dunlap, 1996; Kousis, 1999a; Figueiredo et al., 2001). Se, por um lado, os movimentos ambientalistas formais (e.g. as organizações não-governamentais de defesa do ambiente) têm sido relativamente bem estudados nos países mais desenvolvidos (Lowe e Goyder,

\footnotetext{
${ }^{1}$ Alguns pontos deste texto foram já apresentados no IV Congresso Português de Sociologia (Figueiredo e Fidélis, 2000). A informação empírica que sustenta a análise foi recolhida no âmbito do Projecto Europeu Grassroots Environmental Action and Sustainable Development in Southern EC, financiado pela DGXII (contrato n. ${ }^{\circ}$ EV5V-CT94-0393) e envolvendo a Universidade de Aveiro, a Universidade de Creta e a Universidade de Salamanca.
} 
1983; Yearley, 1992; Dunlap et al., 1993, 1994 e 1995), por outro lado, apenas muito recentemente tais estudos se iniciaram nos países em vias de desenvolvimento e também em Portugal (Rodrigues, 1995; Fidélis et al., 1996; Figueiredo et al., 2001; Nave, 2000 e 2001; Nave e Fonseca, 2000). A maior parte das análises efectuadas no domínio dos movimentos ambientalistas tem-se centrado nos grupos organizados e formais, negligenciando aqueles que se constituem de forma espontânea e informal, i.e., aqueles que podemos designar como movimentos de base popular, que surgem na sequência de conflitos sociais associados a problemas ambientais. Estes movimentos de base popular não apenas se distinguem das organizações formais de defesa do ambiente por surgirem de modo espontâneo e desorganizado, como também por evidenciarem formas de activismo e/ou envolvimento ambiental que escapam aos modos tradicionais e institucionalizados de protesto, sendo geralmente bastante mais radicais (tanto nas suas exigências, como nas suas formas de actuação) do que os movimentos formalmente organizados. Os movimentos de raiz popular distinguem-se ainda de outros pela sua composição interna, pelo nível de compromisso que os seus participantes assumem relativamente ao grupo e/ou comunidade, pela sua duração e pelo delinear das suas estratégias de actuação (Kousis, 2001).

Durante os primeiros anos de democracia, ocorreu em Portugal um largo número de protestos de raiz popular envolvendo questões ambientais. Esse número conheceu, ao longo da década de oitenta, um decréscimo acentuado, para começar a aumentar a partir do início da década de noventa. As oscilações que os dados empíricos revelam associam-se estreitamente aos processos de consolidação da democracia e de estabilização económica, política e social, assim como às alterações observadas na sociedade portuguesa no tocante a valores e atitudes. Tais processos tiveram, no domínio das questões ambientais, consequências importantes relativamente ao envolvimento e participação da sociedade civil. A adesão de Portugal à União Europeia (UE) em 1986 forçou, de certa forma, o Estado a acelerar o processo de produção de legislação no domínio do ambiente, quer no sentido de fazer face aos novos requisitos de carácter ambiental, quer no sentido de consolidar novos padrões de qualidade ambiental. Esta realidade, em associação com o agravamento dos problemas ambientais após o 25 de Abril de 1974 (Mansinho e Schmidt, 1994), com a maior disponibilidade e a maior facilidade de acesso à informação e com a pressão social sobre o desempenho governamental, foram também factores subjacentes ao aumento da acção ambientalista (formal e informal) que se observou em Portugal, sobretudo a partir de finais dos anos oitenta. 
Tendo em conta a escassez de estudos neste domínio, por um lado, e a importância que os movimentos ambientalistas de raiz popular parecem crescentemente assumir na sociedade portuguesa e na generalidade das sociedades ocidentais contemporâneas, por outro lado, pretendemos contribuir para a caracterização daqueles movimentos em Portugal. Os dados empíricos apresentados neste trabalho decorrem da análise de conteúdo das notícias veiculadas por dois jornais de âmbito nacional: o Jornal de Notícias (entre 1974 e 1994) e o Público (entre $1990^{2}$ e 1994). ${ }^{3}$ O último periódico foi seleccionado como fonte de informação essencialmente pelo seu carácter recente, pela sua abordagem inovadora ao contexto nacional da época e pela sua ampla cobertura nacional. O Jornal de Notícias, mau grado seja um jornal mais conotado com a região norte do país, foi seleccionado pelo facto de possuir um caderno local bastante desenvolvido e pormenorizado e que abrange não apenas a referida região como todo o território nacional. A análise documental ${ }^{4}$ desenvolvida encerra algumas limitações cuja maior parte decorre do tipo e da natureza dos documentos estudados. Não apenas se trata de publicações comprometidas com determinados poderes socioeconómicos e políticos que inevitavelmente se reflectem nas suas tendências editoriais e, consequentemente, na exposição e divulgação dos acontecimentos considerados neste trabalho, como se trata de meios de comunicação de massas que contribuem para a construção de um determinada realidade e de determinados discursos sobre essa mesma realidade. A forma como a imprensa (e particularmente os dois jornais consultados) constrói e representa determinadas ocorrências difere substancialmente das práticas concretas dos actores sociais envolvidos nos acontecimentos. Estas últimas só podem ser apreendidas na sua riqueza e profundidade através de estudos de caso, de natureza essencialmente qualitativa. A utilização deste tipo de abordagem, mais centrada em casos de protesto específicos, permitiria um conhecimento mais aprofundado e objectivo dos principais

\footnotetext{
2 Data de início da publicação deste Jornal.

3 Complementarmente, foram analisadas notícias de jornais locais e regionais, designadamente o jornal Diário Regional de Aveiro e Viseu e o jornal Soberania do Povo. A análise das notícias publicadas nestes jornais esteve directamente relacionada com a investigação mais aprofundada de um dos casos de protesto popular na área do ambiente - a proposta de implantação de um aterro de resíduos industriais na localidade de Vagos, no âmbito do projecto do Sistema Nacional de Tratamento de Resíduos Tóxicos Industriais, em 1994, que nunca chegou a ser levada à prática. A análise do caso de protesto referido foi bastante mais aprofundada, através da realização de entrevistas semi-dirigidas a alguns dos seus representantes e dirigentes, bem como às entidades promotoras dos estudos associados à implantação do aterro e a representantes do governo central. Os resultados deste trabalho podem ser consultados em Fidélis et al., 1996.

${ }^{4}$ A metodologia seguida foi comum aos países incluídos no estudo europeu a que já aludimos e centrou-se numa extensa e profunda análise de conteúdo às notícias veiculadas através dos jornais seleccionados (Kousis et al., 1996).
} 
aspectos dos movimentos ambientalistas de carácter informal ou de base popular (Fidélis et al., 1996; Kousis, 1999b; Figueiredo e Fidélis, 2000). Tendo presentes as limitações da informação utilizada e da análise sobre ela efectuada, o trabalho desenvolvido tem forçosamente um carácter exploratório num domínio que consideramos relevante no contexto actual da investigação científica nacional no domínio do ambiente.

\section{O contexto português em matéria de ambiente: a política, a opinião pública e as organizações não-governamentais}

\subsection{A política}

Durante as últimas décadas, e particularmente após a entrada de Portugal na UE, o país enfrentou algumas pressões importantes, potencialmente geradoras de conflitos sociais, no plano do desenvolvimento socioeconómico e da protecção ambiental. Se, por um lado, o esforço político se tem concentrado no alcançar de níveis socioeconómicos semelhantes aos dos restantes países membros da UE, por outro lado, ele tem-se igualmente centrado na necessidade de conciliação de pressões internas e externas relativamente aos padrões de qualidade ambiental. Assim, num primeiro momento, podemos dizer que em Portugal existe a necessidade de resolução de problemas ambientais graves como os associados à poluição das águas e ao armazenamento e tratamento dos resíduos industriais e domésticos e, num segundo momento, observa-se a necessidade de transposição para a cena legislativa nacional das directivas comunitárias e, na sua sequência, de implementação de novos procedimentos técnicos e padrões de qualidade ambiental. Mau grado os esforços que os governos nacionais têm desenvolvido, podemos referir que as prioridades da política ambiental se têm centrado essencialmente nos investimentos para solucionar os problemas mais básicos - designadamente a construção de infra-estruturas básicas associadas ao tratamento de resíduos - e, mais secundariamente, têm tratado os aspectos relacionados com o reforço dos mecanismos para conduzir as diversas actividades produtivas e de consumo à adopção dos novos padrões de qualidade ambiental e de novos mecanismos de resolução dos conflitos ambientais. Apesar do que acabamos de referir, é inegável que, desde finais dos anos oitenta, a política ambiental adquiriu uma importância sem precedentes no nosso país, acompanhada de um acréscimo do debate político e social acerca das questões ambientais. ${ }^{5} \mathrm{~A}$ partir desta data, assistiu-se à definição das principais orientações, estratégias e instrumentos de política no que diz

\footnotetext{
5 A propósito da análise da inserção da temática ambiental no discurso e na prática políticos, cf. Figueiredo e Martins, 1996b.
} 
respeito ao ambiente. ${ }^{6}$ Durante as últimas duas décadas, foi publicada em Portugal uma grande diversidade e quantidade de legislação ambiental. No entanto, a maior parte dos instrumentos legislativos não se encontra ainda regulamentada e/ou implementada, não estando igualmente consolidados (frente às expectativas e necessidades sociais criadas) os instrumentos técnicos e financeiros atribuídos à política nacional de ambiente. Assim, se, por um lado, podemos considerar que em Portugal se encontram criadas as condições formais necessárias à existência de uma efectiva política ambiental (Marques, 1994; Eloy, 1994; Mansinho e Schmidt, 1994), ${ }^{7}$ verifica-se, por outro lado, que não existe uma prática coerente e sólida de aplicação dos mecanismos legais que a legislação configura ${ }^{8}$. A descontinuidade e as contradições observadas podem, parcialmente, ser explicadas pelo que Boaventura de Sousa Santos designa por condição semiperiférica de Portugal no contexto europeu, a qual, entre muitos outros aspectos, faz emergir um Estado paralelo ou subterrâneo, i.e. "um Estado que se compromete formalmente com um certo padrão de legalidade e de regulação social, mas se descompromete dele por omissão ou por vias informais" (Santos, 1990: 21). Esta importante diferença entre o quadro legislativo ("law in books") e as práticas institucionais e sociais associadas ("law in action") é uma característica fundamental da acção do Estado português no domínio do ambiente como em outros (Santos, 1990). Esta espécie de demissão e autonegação do Estado relativamente aos instrumentos legais que ele próprio cria assume diversas formas que podem variar desde a tolerância face ao desrespeito da lei, até à violação e à aplicação selectiva da mesma (Santos, 1990).

\footnotetext{
${ }^{6}$ Como sabemos, e como refere, entre outros autores, Boaventura de Sousa Santos (1990), a existência destes mecanismos não é garantia, por si só, da sua eficácia.

7 Designadamente no que se refere às condições formais, Portugal reúne: a consagração constitucional do direito do ambiente; uma lei de bases específica (desde 1987, a Lei n. ${ }^{\circ} 11 / 87$ de 7 de Abril); a circunstância de se produzirem, desde 1987 também, relatórios regulares sobre o estado do ambiente por "autoridades técnica e cientificamente competentes" (Marques, 1994: 110); um ministério que tutela o ambiente de forma específica, reconhecendo-se assim, de certa forma, a importância deste assunto; e ainda a interface entre o governo e a sociedade civil estabelecida pelo Instituto de Promoção Ambiental.

${ }^{8}$ A este propósito, ver também o trabalho de José Manuel Pureza (1997: 9-10), cuja hipótese de partida é, justamente, a discrepância observada em Portugal entre a "afirmação normativa do Direito do Ambiente e a sua assimilação nas práticas dos actores sociais e do sistema judicial”. Como refere o mesmo autor "se, por um lado, a abundante produção de instrumentos legislativos vocacionados para a defesa do ambiente contribui para a sua autonomização como bem jurídico e para a consagração formal do direito do ambiente como um direito fundamental, por outro, as características da sociedade portuguesa, como sociedade de desenvolvimento intermédio colocam este direito emergente, em primeiro lugar, à margem do núcleo de direitos experimentado como imprescindível pela maioria dos cidadãos (não suscitando, por isso, movimentos sociais fortes e organizados em torno da sua defesa) e, consequentemente, coloca-o fora das prioridades garantísticas e da especialização funcional dos tribunais portugueses, precarizando-o".
} 


\subsection{A opinião pública}

Tal como vários outros aspectos, as questões ambientais como preocupação social emergiram em Portugal bastante mais tarde do que em outros países ocidentais. Apesar desta entrada tardia do ambiente nas preocupações sociais (que, de acordo com vários autores, pode ser situada no início da década de noventa $)^{9}$ e apesar da elevada heterogeneidade das representações e práticas sociais observadas em Portugal (Santos, 1990; Reis e Lima, 1998), os dados empíricos existentes ${ }^{10}$ sugerem claramente que o ambiente tem um lugar de destaque entre as preocupações da opinião pública nacional. O ambiente é, mais precisamente, colocado como um dos principais problemas do país, imediatamente a seguir a problemas como a droga, o desemprego, a saúde e a pobreza e exclusão social. É também entendido como mais importante do que questões sociais relevantes associadas ao custo de vida, à segurança/violência, à habitação e ao ensino/educação (Schmidt et al., 2000). ${ }^{11}$ Os dados produzidos pela CCE (1986, 1988, 1992, 1995 e 1999) demonstram que os portugueses tendem a identificar os problemas ambientais num contexto de defesa de valores de tipo materialista, ou seja, num contexto em que são sobretudo valorizados aspectos como o crescimento e a estabilidade económica, a segurança física e a saúde (Lowe e Goyder, 1983; Inglehart, 1990, 1997).

Apesar da relativamente forte presença de valores ambientalistas que os dados das sondagens e investigações referidas sugerem, as atitudes "verdes" dos portugueses ainda reflectem alguma fragilidade (CCE, 1986, 1988, 1992, 1995 e 1999; Schmidt et al., 2000). Tal fragilidade é particularmente nítida se atentarmos no tipo de problemas ambientais que os portugueses consideram mais graves, assim como na descontinuidade observada entre atitudes e práticas ambientais (Figueiredo e Martins, 1999). Embora as atitudes sejam fortes, as práticas ou comportamentos a elas associados podem ser caracterizadas como frágeis e pontuais e não consistentes com uma efec-

\footnotetext{
9 Entre os trabalhos que nos permitem abordar a emergência do ambiente como uma questão social relevante em Portugal, destacamos os de Mansinho e Schmidt (1994), de Figueiredo e Martins (1996a e 1996b) e de Schmidt et al. (2000).

${ }^{10}$ Existem já bastantes dados empíricos quanto aos níveis de preocupação ambiental dos cidadãos nacionais (e ao conteúdo da mesma). Para isso foram fundamentais as sondagens levadas a cabo pela CCE desde 1986, assim como a criação do Observa - Ambiente, Sociedade e Opinião, em 1996. ${ }_{11}$ A opinião pública nacional, a exemplo do que acontece na maior parte dos países ocidentais e no que se refere à formação de preocupação ambiental, tem sido influenciada por factores diversos, tais como a publicidade, os mass media, o discurso político, a acção das associações de defesa do ambiente, entre outros (Figueiredo e Martins, 1996a). Particularmente a revolução mediática ocorrida em Portugal no início dos anos noventa (com o surgimento dos canais privados de televisão, de novos jornais, etc. e com a concorrência estabelecida entre estes meios de comunicação) contribuiu de modo decisivo para a formação de uma sensibilidade ambiental na globalidade da sociedade portuguesa.
} 
tiva consciência ambiental. ${ }^{12}$ Esta fragilidade manifesta-se, designadamente, na fraca adesão a organizações formais de defesa do ambiente e na ausência de participação neste domínio. Como referem Garcia et al. (2000), muito embora $58 \%$ dos cidadãos nacionais se considerem simpatizantes do movimento ambientalista, apenas $14 \%$ são membros de uma associação de defesa do ambiente (e destes apenas $5 \%$ são, de facto, activistas).

Os inquéritos e sondagens de opinião mencionados anteriormente evidenciam igualmente que a sensibilidade para as questões ambientais em Portugal tende a aumentar com a complexificação urbana, nos estratos sociais mais elevados e nos escalões etários mais baixos (Mansinho e Schmidt, 1994; CCE, 1982, 1986, 1988, 1992, 1995 e 1999; Figueiredo e Martins, 1999; Schmidt et al., 2000). Por outro lado, as mesmas fontes evidenciam que os habitantes rurais e os habitantes urbanos ${ }^{13}$ possuem uma sensibilidade diferente relativamente às questões ambientais. Assim, enquanto os habitantes das áreas rurais apontam como problemas ambientais mais graves os que se referem às carências no domínio do saneamento básico e da recolha e tratamento de resíduos (i.e., normalmente os que se associam à sua vivência quotidiana), os habitantes urbanos referem sobretudo problemas associados à poluição atmosférica, à ausência de espaços verdes (também associados ao seu quotidiano) e ainda as questões ambientais mais mediatizadas como a destruição da camada de ozono, o efeito de estufa e as alterações climáticas. Isto significa que, para além de os níveis e tipos de preocupação ambiental se associarem de perto com as características objectivas dos indivíduos, eles também se relacionam intimamente com o quadro de vida quotidiano.

\subsection{As organizações não-governamentais na área do Ambiente}

O desenvolvimento das organizações ambientalistas está igualmente relacionado com as características globais do nosso país. O longo período de ditadura vivido em Portugal conduziu àquilo que António Reis (1994) designa como anestesia cívica que parece caracterizar a sociedade portuguesa até aos nossos dias. O mesmo processo pode ser observado na forma como se constituíram e desenvolveram as organizações não-governamentais na área do ambiente.

Em Portugal, as associações de defesa do ambiente apenas adquiriram relevância junto da opinião pública a partir de finais da década de oitenta.

\footnotetext{
12 A propósito desta questão, cf. Mormont, 1993. De uma forma geral, podemos referir que o que distingue a consciência da sensibilidade ambientais é o facto de a primeira implicar uma relação coerente entre atitudes e comportamentos e a segunda indiciar apenas a atitude e a preocupação. ${ }_{13}$ Dizemos habitantes rurais e urbanos estando conscientes da diversidade que cada uma destas categorias encerra.
} 
Antes disso, apesar do aumento do seu número, a sua acção era muito limitada e pouco expressiva no tocante tanto à capacidade de influenciar a opinião pública como de exercer pressão junto dos poderes e organismos políticos e administrativos. Até 1974, a acção de defesa do ambiente organizada era praticamente inexistente. ${ }^{14}$ Frequentemente, esta ausência é explicada pela existência, até aquela data, de um regime político autoritário em Portugal que eliminava efectivamente qualquer tentativa de organização pública e social, assim como se sustentava numa circulação limitada da informação e em múltiplos mecanismos de censura (Melo e Pimenta, 1993), para não mencionar também os baixos níveis de rendimento e de capital escolar da generalidade da população portuguesa. Por outro lado, como referem, entre outros autores, Melo e Pimenta (1993) e Mansinho e Schmidt (1994), até 1974 os problemas ambientais nacionais tinham uma expressão limitada e encontravam-se muito localizados, devido essencialmente à industrialização e urbanização débeis do país. Após 1974, e até meados da década de oitenta, o número das organizações formais de defesa do ambiente conheceu um aumento importante, sendo que a sua acção extravasava as causas ambientais, focando aspectos políticos e sociais (Rodrigues, 1995). ${ }^{15}$ Segundo a mesma autora, a evolução dos movimentos ambientalistas formais em Portugal pode ser sintetizada em quatro fases principais:

- A primeira (entre 1974 e 1976) caracterizada pelo surgimento e desaparecimento súbito de numerosas associações. Estas debatiam-se com diversos tipos de problemas, desde a falta de capacidade organizativa até à dificuldade de aceitação pública da mensagem ecologista;

- A segunda, que pode ser situada entre 1976 e 1983, associa-se aos protestos organizados contra a ameaça do nuclear. Nesta fase, o discurso ecologista é marcado pelo radicalismo político que também dominava a sociedade portuguesa. É neste período que surge a primeira organização política de carácter ecologista - o Partido Os Verdes (fundado em 1982);

- A terceira fase compreende o período entre 1984 e 1988. É um período marcado pelo crescimento da estabilidade económica, social e política. A adesão de Portugal à UE facilitou, paralelamente, novas estratégias de actuação das associações de defesa do ambiente. O acontecimento mais marcante desta fase foi a publicação, em 1987, da Lei de Bases do Ambiente (Lei n. ${ }^{\circ} 11 / 87$, de 7 de Abril) e, particularmente, da Lei de Bases das Associa-

\footnotetext{
${ }^{14}$ A Liga para a Protecção da Natureza (LPN) foi o primeiro grupo de defesa do ambiente nacional. Criada em 1948, a sua actividade foi impulsionada por cientistas ligados a movimentos internacionais de conservação da natureza (Mansinho e Schmidt, 1994).

${ }^{15}$ Segundo a autora mencionada, o Movimento Ecologista Português (MEP) é um exemplo paradigmático desta situação, batendo-se contra os modelos de desenvolvimento orientados para o capitalismo e consumismo.
} 
ções de Defesa do Ambiente - LBADA (Lei n. ${ }^{\circ}$ 10/87, de 7 de Abril). De acordo com Melo e Pimenta (1993), estas leis consagraram em definitivo o ambiente como assunto institucional e socialmente relevante. Como referem Nave e Fonseca (2000: 5), a LBADA dotou os grupos ambientalistas do "estatuto legal necessário para participar na qualidade de 'parceiros sociais' aos mais diversos níveis dos processos de elaboração, negociação e decisão da área das políticas públicas do ambiente”. À legislação mencionada junta-se o facto de o ano de 1987 ter sido o Ano Internacional do Ambiente, permitindo a criação de diversos grupos de defesa do Ambiente assim como a consolidação de preocupações sociais e políticas com a educação ambiental;

- Depois de 1989 e até à actualidade, assistimos ao nascimento do que pode ser designado como uma nova era e cujas principais características foram a criação da Confederação Nacional das Associações de Defesa do Ambiente e a aprovação, em 1998, da proposta de Lei que define o Estatuto das Organizações Não-Governamentais de Ambiente. De certo modo, esta fase corresponde a um período de alteração das próprias estratégias de actuação das associações de defesa do ambiente (Melo e Pimenta, 1993) e à sua institucionalização (Nave e Fonseca, 2000). ${ }^{16}$

O Quadro 1 mostra-nos a distribuição das associações de defesa do ambiente por região e permite uma comparação com o número de protestos populares ocorridos na mesma região e que serão caracterizados na secção seguinte. Os dados constantes do quadro mostram a concentração das associações de defesa do ambiente na região de Lisboa e Vale do Tejo. Os protestos populares têm, por seu lado, uma maior expressão (globalmente considerados) nas regiões Norte e Centro do país.

QUADRO 1 - Distribuição Regional das Associações de Defesa do Ambiente e dos Protestos Populares

\begin{tabular}{lcccc}
\hline \multicolumn{1}{c}{ Regiões } & N. ${ }^{\circ}$ de ADA's & $\%$ & $\begin{array}{c}\text { N. }{ }^{\circ} \text { de protestos } \\
\text { populares }\end{array}$ & $\%$ \\
\hline Norte & 27 & 25.0 & 221 & 40.4 \\
Centro & 18 & 16.7 & 136 & 24.8 \\
Lisboa e Vale do Tejo & 47 & 43.5 & 148 & 27.0 \\
Alentejo & 10 & 9.3 & 21 & 3.8 \\
Algarve & 6 & 5.5 & 22 & 4.0 \\
\hline \multicolumn{1}{c}{ Total } & $\mathbf{1 0 8}$ & $\mathbf{1 0 0}$ & $\mathbf{5 4 8}$ & $\mathbf{1 0 0}$ \\
\hline
\end{tabular}

Fonte: Ipamb (1996); Kousis, Aguilar e Fidélis (1996)

16 Nave e Fonseca (2000) e Nave (2000) demonstram que esta institucionalização colocou alguns problemas às organizações formais de defesa do ambiente, desde a sua capacidade interna para responder aos novos desafios até à sua dependência da Administração Pública. 


\section{Os movimentos ambientais de raiz popular em Portugal (1974-1994)}

Esta secção tem por objectivo a análise dos participantes, formas de protesto desenvolvidas e exigências colocadas a diversas instituições e organismos no âmbito dos movimentos de protesto popular. Como tivemos ocasião de referir na introdução, distinguimos este tipo de movimentos ambientais de raiz popular das organizações formais de defesa do ambiente não apenas pelo seu carácter espontâneo, mas igualmente pelo tipo de acções que desenvolvem, pela sua duração e continuidade das suas intervenções.

De forma muito sintética, e ressalvando novamente a relativamente limitada investigação neste domínio, os protestos populares na área do ambiente envolvem geralmente uma enorme variedade de grupos sociais e socioprofissionais (Freundenberg e Steinsapir, 1992; Taylor, 1995; Kousis, 1999a). Os autores mencionados referem igualmente que a maior parte dos movimentos de tipo grassroots é muito marcada por aspectos e preocupações que podemos designar como materialistas e/ou antropocêntricos e relacionados com a defesa da saúde humana e da propriedade privada. Alguma preocupação é também evidenciada no que concerne aos impactes dos projectos ou decisões que afectam o valor económico das propriedades, os rendimentos das actividades económicas e a preservação dos ecossistemas locais.

A maioria dos protestos populares associados a estes movimentos informais tende a ser de tipo não violento. Em geral, os participantes nestes protestos utilizam preferencialmente formas alternativas de participação, tais como bloqueio de estradas, piquetes nos locais de implantação dos projectos e manifestações públicas (Taylor, 1995; Fidélis et al., 1996; Figueiredo e Fidélis, 2000; Figueiredo et al., 2001; Kousis, 1999a). Outra conclusão das investigações mencionadas é a aproximação dos participantes nestes movimentos a vários organismos e agentes, incluindo o próprio Estado, no sentido de captarem a sua atenção e apoio para a resolução dos problemas subjacentes aos protestos. Os mass media são igualmente abordados pelos participantes como parceiros importantes na divulgação dos problemas.

Foram analisados 550 casos de protestos populares de natureza ambiental $^{17}$, ocorridos entre 1974 e 1994 . O número de artigos e notícias dedicados a cada caso variou entre um (em $57,8 \%$ dos casos) e três (em 7,5\% das ocorrências). O maior caso de protesto identificado foi abordado em 53 artigos e relacionou-se com a implantação de um aterro de tratamento

\footnotetext{
${ }^{17}$ Quando dizemos natureza ambiental temos subjacente um entendimento de ambiente que ultrapassa os elementos naturais e que se refere às interacções entre o Homem e o meio natural. Neste sentido, todos os casos analisados, ainda que não envolvessem directamente a natureza, foram seleccionados pelo facto de as decisões e/ou projectos possuírem impactes ambientais e pela circunstância de estes serem considerados relevantes pelos participantes nos protestos.
} 
de resíduos industriais. Pela análise de conteúdo efectuada às notícias veiculadas pelos jornais considerados, observamos que os casos de protesto popular têm uma duração limitada no tempo $(64,9 \%$ teve uma duração de um a dois dias; $13,5 \%$ entre um a dois anos e 1,6\% uma duração superior a vinte anos). Tendo em conta a distribuição dos casos ao longo do tempo, verificamos que mais de metade ocorreram na década de noventa $(53,5 \%)$, particularmente entre 1991 e 1994. Entre 1974 e 1980, ocorreram 14,2\% dos casos analisados e, ao longo da década de oitenta, apenas 5,1\%. A larga maioria dos casos que observámos envolveu apenas uma comunidade $(77,3 \%)$, sendo que apenas $22,7 \%$ ultrapassaram as fronteiras locais, envolvendo duas ou mais comunidades. A articulação destes dados com o tipo de projecto e/ou actividade motivadora dos protestos permite-nos verificar que a maior parte desses projectos e/ou actividades apenas têm influência ao nível local. $53 \%$ dos casos analisados possuem uma natureza rural, sendo que $31,5 \%$ ocorreram em áreas urbanas. Estes resultados parecem ir ao encontro do que referem Freundenberg e Steinsapir (1992), Schnaiberg (1992) e Kousis (1999b e 2001) relativamente ao carácter localista da maior parte dos movimentos ambientais de raiz popular. Estes autores salientam, efectivamente, o carácter geograficamente limitado deste tipo de movimentos. No entanto, ainda que possamos afirmar que o carácter rural da maior parte dos protestos analisados reforça o seu localismo, esta característica tende também a distinguir o nosso país dos restantes países da Europa do Sul considerados no estudo - a Grécia e a Espanha - (Kousis, 1999b). Esta diferença poderá ser explicada por diversos factores, designadamente a maior disponibilidade de solo fora das áreas urbanas para a implantação de determinados projectos; os menores capitais escolares e de participação cívica que em geral se observam nas áreas rurais portuguesas e também os factores culturais associados à insegurança perante a mudança que acentuam a suspeição relativamente ao exterior e às novas tecnologias e/ou actividades. Por outro lado, a maior ligação das populações rurais à terra, por razões afectivas e económicas, e a geralmente maior coesão social que promove redes e laços de solidariedade mais consistentes e duradouros nestas áreas poderão estar igualmente subjacentes ao mais elevado número de protestos observados. Estes aspectos parecem ser, aliás, mais determinantes para os protestos do que a própria sensibilidade ecológica das áreas de implantação dos projectos/actividades e mesmo mais do que a valorização dos recursos naturais locais. A clarificação e compreensão destes aspectos justificam uma investigação e um estudo empírico mais aprofundados.

A maioria dos artigos analisados não faz qualquer referência ao número de participantes nos protestos. Para os poucos casos em que tal informação 
se encontra disponível, verificamos que $8 \%$ dos protestos mobilizaram entre 100 e 1000 indivíduos e 3,8\% entre 1001 e 2000 participantes, sendo que apenas três casos envolveram mais de 5000 pessoas. Relativamente ao tipo de participantes nos protestos (ver Figura 1), a informação empírica permite-nos concluir uma vez mais pelo carácter extremamente localizado dos movimentos ambientais de base popular.

Assim, os residentes (84\%) e os órgãos de governo local $(33,5 \%)^{18}$ são o tipo de participante mais frequente naqueles movimentos. Também os grupos de defesa do ambiente de natureza local $(24,7 \%)$ e os sindicatos $(18,5 \%)$ possuem algum significado. Os participantes recorrem com pouca frequência às associações formais de defesa do ambiente de âmbito nacional. Efectivamente, estes movimentos tendem a desenvolver uma acção mais vasta, temporal e geograficamente, revelando ao mesmo tempo preocupações ambientais que extravasam largamente os interesses particulares ou locais. Neste sentido, podemos dizer com Kousis (2001: 131-132) que os movimentos de base popular "diferem das organizações ambientalistas formais, no modo como lidam com os problemas ambientais que enfrentam. Enquanto as associações formais aligeiraram ${ }^{19}$ as suas tácticas face aos actores poderosos que controlam as fontes e as actividades que lhes permitem intervir no ecossistema, os grupos de base popular permanecem bastante mais confrontacionais, desafiando directamente aqueles actores".

FIGURA 1 - Participantes nos casos de protesto ${ }^{20}$

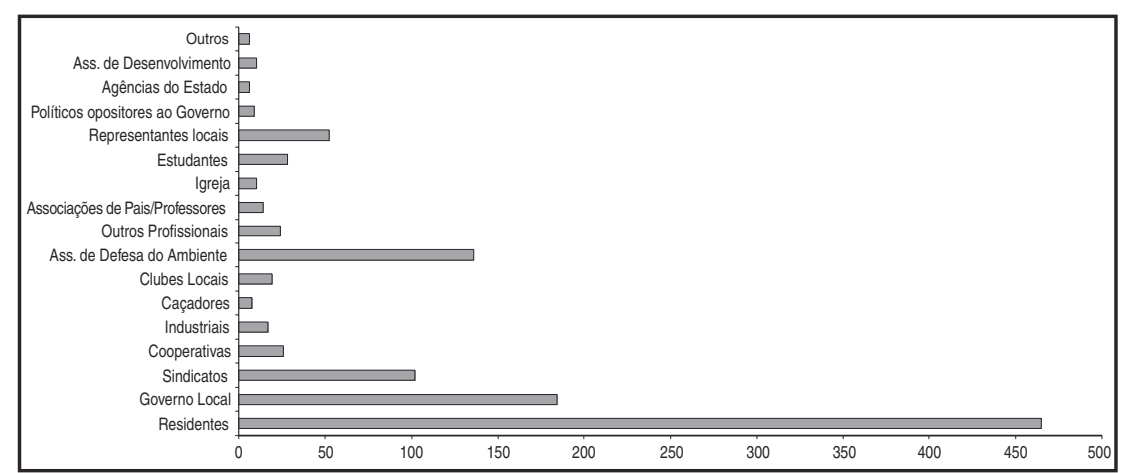

\footnotetext{
${ }_{18}$ Aqui incluem-se principalmente os presidentes das Juntas de Freguesia.

19 Este aligeiramento ou, pelo menos, uma alteração de estratégia das associações de defesa do ambiente neste sentido, é referido para o caso português por Melo e Pimenta (1993), por Nave (2000) e por Nave e Fonseca (2000).

${ }^{20}$ Todas as figuras apresentadas nesta secção possuem como fonte Kousis et al., 1996.
} 
Tal como pode ver-se na Figura 2, as acções de protesto mais frequentes referem-se a exigências e queixas públicas $(94,7 \%)$. Outras acções utilizadas pelos movimentos ambientais de base popular no decorrer dos protestos são a apresentação de reclamações a autoridades públicas $(74,7 \%)$ e a realização de abaixo-assinados $(45,6 \%)$.

FIGURA 2 - Acções desencadeadas durante os protestos

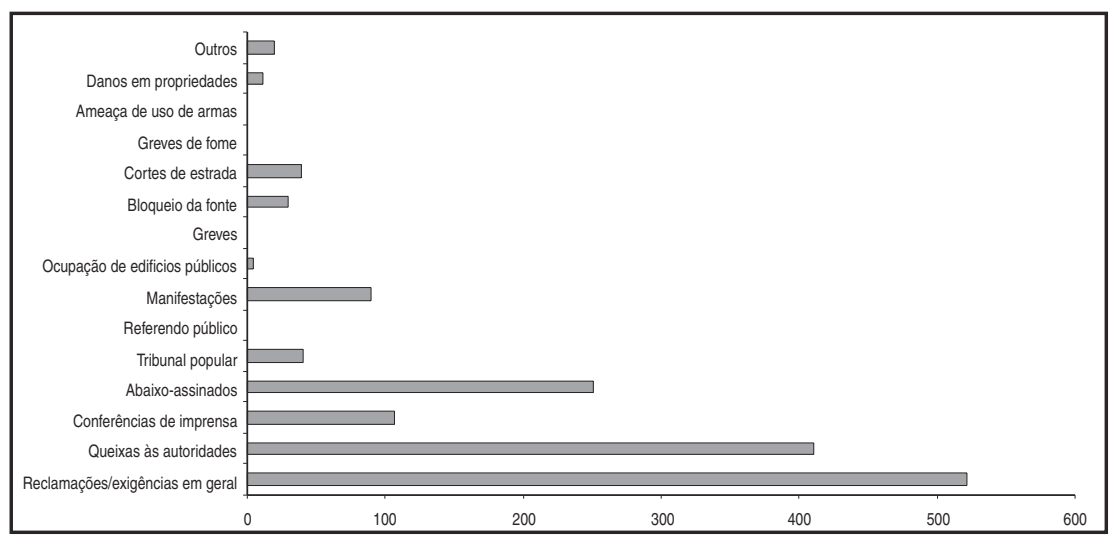

Os dados constantes da figura precedente reflectem que os casos de protesto popular na área do ambiente, em Portugal, possuem um carácter pacífico e não violento. Apesar desta conclusão genérica, observa-se que, em alguns casos, foram desenvolvidas acções que reflectem níveis mais elevados e extremados de protesto. Entre estes salientamos as manifestações e assembleias populares (acção realizada em 16,4\% dos casos), os cortes de estradas (em 7,5\%) e o bloqueio do acesso de especialistas e investigadores aos locais de implantação dos projectos/actividades (em 5,5\%). No mesmo sentido, verificamos que apenas $10 \%$ dos 550 casos analisados envolveram, no decurso dos protestos, algum episódio de violência.

Os participantes não locais nos protestos são, como temos vindo a referir, tanto para os casos analisados neste trabalho como para a generalidade dos movimentos de raiz popular investigados por outros autores, em número e diversidade bastante reduzidos. Assim, os dados empíricos demonstram que apenas em 9,6\% dos casos os participantes locais contaram com o apoio de associações de defesa do ambiente de âmbito nacional. Apenas em 5,3\% dos casos de protesto se registou o envolvimento de residentes de áreas vizinhas à comunidade local. Estes valores, como referido, são bastante reduzidos e vêm reforçar a natureza localizada destes protestos, aos seus mais diversos níveis, tal como o seu carácter 
Nimby ${ }^{21}$. A fraca adesão aos movimentos de raiz popular por parte de actores e agentes não locais demonstra, em certa medida, que estas formas de envolvimento público se encontram, no nosso país pelo menos, ainda muito condicionadas pela defesa dos interesses locais e/ou privados. Sendo este o caso, as causas que conduzem aos protestos apenas parecem possuir capacidade de mobilizar os actores sociais, políticos e económicos ao nível local, não passando da fase de no meu quintal, não, para a fase no quintal seja de quem for, não (i.e. da fase Nimby para a fase Niaby - not in anyone's backyard). Esta não passagem é identificada por certos autores (e.g. Freundenberg e Steinsapir, 1992) como uma das principais características dos movimentos ambientais de base popular. A fraca capacidade de mobilização apontada pode também ser parcialmente explicada por outros factores, nomeadamente pela forma espontânea como estes protestos surgem, pela generalizada ausência de organização das acções e do movimento e ainda pela informalidade da maior parte das acções desencadeadas pelos participantes.

As causas dos protestos populares que estão na base dos movimentos grassroots em Portugal (cf. Figura 3) relacionam-se com diversos aspectos, tais como as questões de recolha e tratamento de resíduos (em 34\% dos casos), a construção de infra-estruturas $(9,8 \%)$ e a conservação da natureza e construção ou actividade de instalações ligadas à produção de energia ( $9 \%$ em cada um dos casos).

FIGURA 3 - Principais causas dos protestos

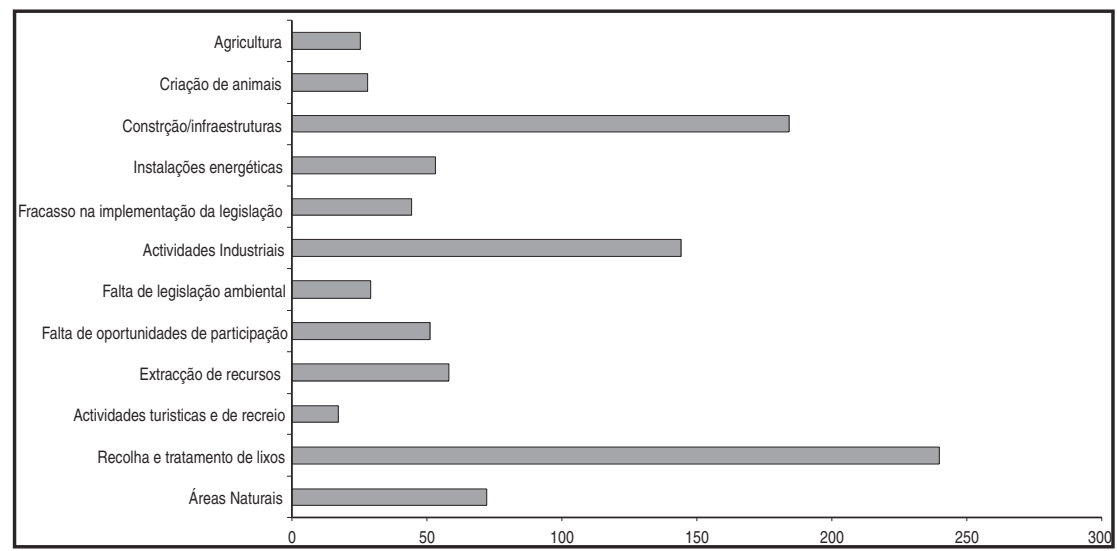

${ }^{21}$ Nimby significa "not in my backyard" ou "no meu quintal, não". Esta expressão tem sido utilizada essencialmente para designar e caracterizar as atitudes de rejeição popular a determinados projectos e/ou intervenções públicas e privadas no domínio do ambiente e do desenvolvimento (Yearley, 1992; Freudenberg e Steinsapir, 1992; Freundenburg e Pastor, 1992). 
Estas causas reflectem, em certa medida, o perfil económico do país e o seu desenvolvimento nas últimas décadas, sobretudo no que se refere à situação de recolha e tratamento de resíduos (industriais e domésticos) que se vive desde há alguns anos em Portugal. Em 34\% dos casos de protesto analisados, os mobilizadores e participantes dos movimentos consideram a recolha e tratamento de resíduos como a única causa responsável pelos impactes que percepcionam como negativos, exigindo a adopção de medidas de mitigação desses mesmos impactes. Em 31,3\% dos protestos é considerado que a fonte desses impactes deveria ser encerrada (se se trata de um actividade já instalada) ou não construída (quando se trata de um projecto de instalação). As exigências dos participantes nos protestos revelam a desconfiança (comum à maioria destes movimentos de raiz popular) nas autoridades políticas e nos cientistas, no que se refere à aplicação da legislação ambiental, à intervenção do estado e aos sistemas de controlo e/ou mitigação dos impactes negativos. Como é referido por Figueiredo et al. (2001), estes movimentos de base popular desenvolvem com frequência uma atitude ambivalente em relação aos cientistas e técnicos envolvidos nos projectos/actividades. Assim, enquanto se observam níveis elevados de cepticismo relativamente aos cientistas e técnicos associados aos pro motores dos projectos/actividades (e.g. os cientistas e técnicos relacionados com os estudos de localização e de estudos de impacte ambiental e socioeconómico), existe uma confiança ilimitada nos experts que apoiam os protestos e que, de alguma forma, sustentam a argumentação dos manifestantes. ${ }^{22}$

A Figura 4 apresenta dados relativos às soluções avançadas pelos participantes nos casos de protesto. Observamos, assim, que a não realização dos planos é proposta como solução em $34,4 \%$ dos casos. Esta proposta pode ser considerada como a mais directa e fácil de alcançar e também aquela que requer menores níveis de conhecimentos científicos e técnicos no que aos projectos e actividades diz respeito. Em $25 \%$ dos casos, é proposta como solução a utilização de tecnologias menos poluentes e, em $24 \%$ dos protestos, a única solução avançada é a paragem da actividade geradora dos conflitos. Este tipo de propostas associa-se directamente aos casos de implantação e menos aos casos de exposição, i.e., na generalidade dos casos em que são avançadas soluções pelos participantes, trata-se de protestos desencadeados antes da instalação do projecto/actividade.

\footnotetext{
22 Ainda que o caso não tenha sido por nós analisado (por estar fora do âmbito temporal deste projecto), cremos que o recente caso da implementação de um sistema de co-incineração de resíduos industriais perigosos em Souselas demonstra esta ambivalência relativamente aos cientistas e aos técnicos.
} 
FIGURA 4 - Soluções propostas pelos participantes nos protestos face ao projecto/actividade

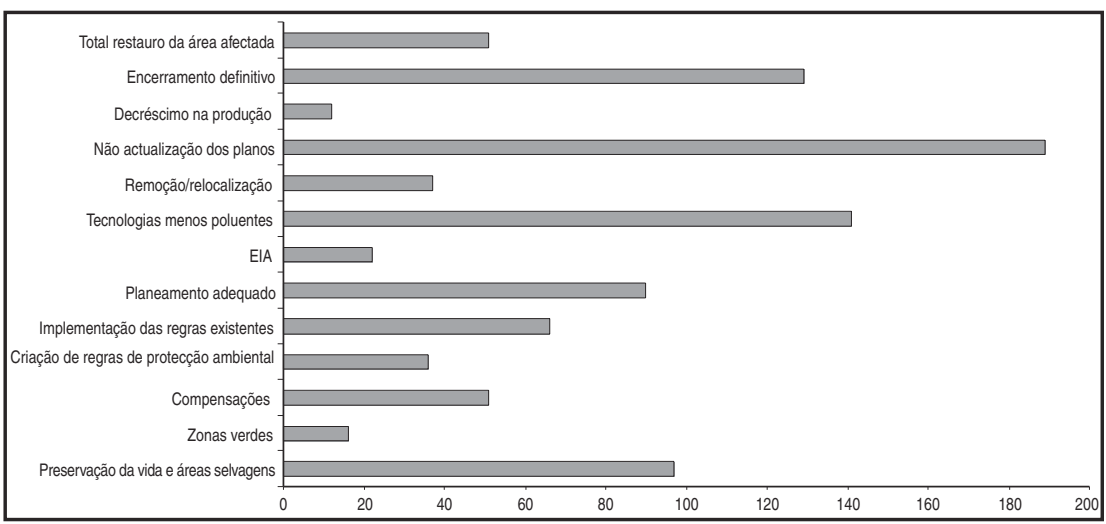

Segundo Maria Kousis (2001), quando estão em causa impactes percepcionados como mais graves pelos intervenientes nos protestos, estes tendem a abordar uma grande diversidade de actores e agentes sociais e institucionais, no sentido de procurar apoio para a resolução daqueles impactes. Segundo Freundenberg e Steinsapir (1992) e ainda Cable e Cable (1995), os participantes neste tipo de protestos fundamentam as suas acções nas respostas que obtêm dos actores e organismos abordados e fazem depender dessas respostas a continuidade dos próprios movimentos. A Figura 5 mostra-nos quais os actores e agentes abordados como apoiantes pelos participantes nos protestos populares de natureza ambiental ocorridos em Portugal. As Câmaras Municipais são os interlocutores a que se recorre com mais frequência (mas apenas em 14\% dos casos), seguidas pelo governo central e pelas Juntas de Freguesia. Esta procura de apoio institucional junto de agentes políticos com elevada capacidade de intervenção e decisão (e.g. as câmaras municipais e o governo central) reforça a sugestão de Kousis (1999b) no que se refere ao aumento do número de protestos antes ou durante períodos eleitorais. Este aumento é justificado pela autora como tendo subjacente a percepção de uma maior receptividade e apoio que podem ser obtidos durante estes períodos relativamente às exigências e necessidades sociais.

A maior parte dos artigos analisados não faz referência ao tipo de respostas obtidas através destes actores e organismos. Ainda assim, a informação disponível permite-nos observar o carácter geralmente positivo das respostas dos actores e agentes contactados para apoiarem os movimentos de protesto. No entanto, estas respostas positivas associam-se menos a acções concretas por parte dos actores abordados e mais à possibilidade da sua avaliação. 
FIGURA 5 - Actores e agentes abordados para apoiar os protestos

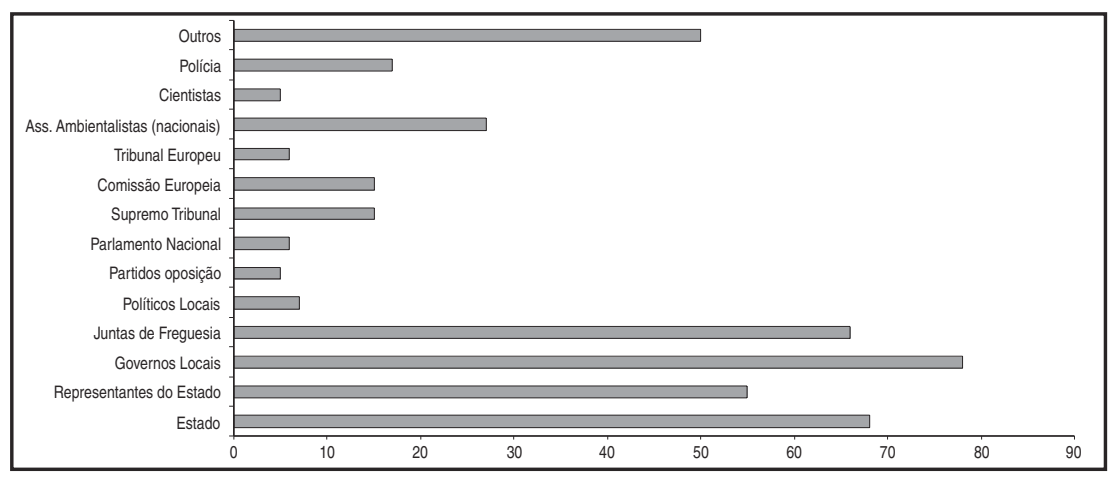

Curiosamente, os actores e agentes considerados responsáveis pelo desencadear dos protestos são, em grande medida, os mesmos a quem é pedido apoio. Como podemos observar na Figura 6, o governo central e os governos locais são os agentes mais desafiados durante os protestos populares de natureza ambiental que analisámos, a par com os produtores privados, nomeadamente os industriais. Kousis (2001) refere que o Estado, nos seus diversos níveis, é frequentemente colocado em causa ou desafiado pelos participantes nos protestos por duas ordens de razões:

- Em primeiro lugar, porque o Estado tende a permitir ou a possibilitar a exploração dos recursos ambientais pelos produtores privados, pelo seu valor de troca;

- Em segundo lugar, o Estado tem por dever a preservação do ambiente e da capacidade dos ecossistemas, para que estes possam ser encarados como valores de uso pelos cidadãos.

FIGURA 6 - Actores e agentes desafiados durante os protestos

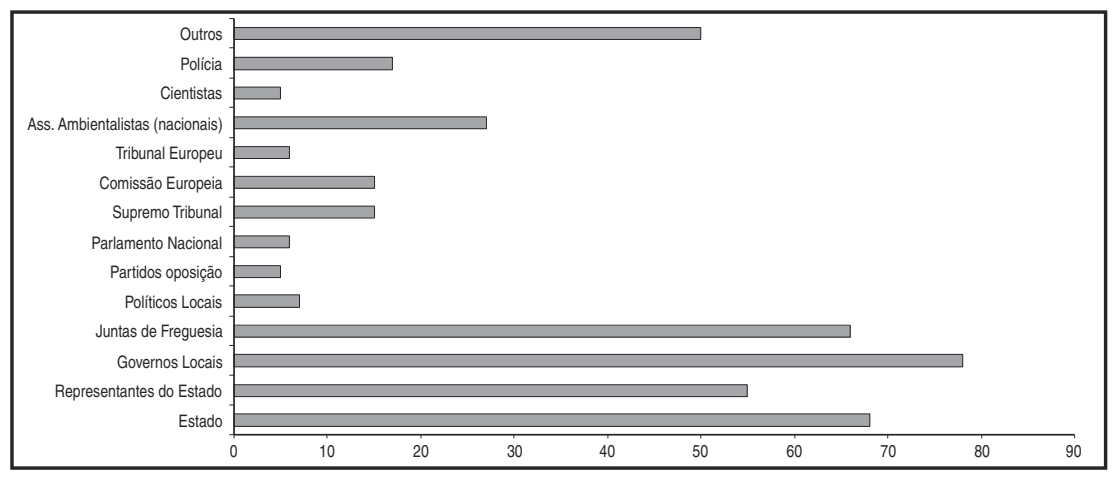


Os dados constantes da figura anterior reflectem a importância e o lugar que são atribuídos aos principais actores envolvidos nos processos de desenvolvimento nacional, das últimas décadas, Por um lado, o Estado e os seus agentes são responsáveis pela construção de infra-estruturas, como estradas, redes de abastecimento de água, sistemas de tratamento de resíduos, entre outros, sendo que nessa condição se constituem como agentes importantes a serem desafiados ou postos em causa durante os protestos populares. Por outro lado, o Estado e os seus agentes são considerados responsáveis pela minimização ou solução das questões que conduziram aos protestos, já que são os organismos que dispõem não apenas da responsabilidade, mas também da capacidade de decidir e fazer accionar os mecanismos e instrumentos legais necessários para a resolução dos conflitos. Esta posição dual do Estado faz com que ele seja simultaneamente percepcionado e abordado como responsável pelo problema na origem dos protestos e como solucionador desse mesmo problema.

As propostas de desenvolvimento em domínios como a implementação de actividades industriais, que também se constituem como causas de alguns protestos, como vimos anteriormente, decorrem sobretudo da iniciativa de promotores privados e nesse sentido eles surgem como agentes desafiados também com alguma frequência pelos movimentos ambientais de raiz popular.

Mais uma vez, a informação obtida através da análise de conteúdo dos artigos dos jornais é limitada no que se refere às respostas deste grupo de actores e agentes postos em causa pelos participantes nos protestos. ${ }^{23} \mathrm{Com}$ base na informação disponível, concluímos que a maior parte das respostas dadas por este grupo de agentes é de natureza positiva. Contrariamente ao que seria de esperar, os promotores privados dão mais frequentemente respostas positivas do que negativas. ${ }^{24}$ Dos dados analisados, resulta ainda que os actores e agentes interessados no valor de uso dos ecossistemas locais (residentes e governos locais) entram em conflito com os actores e agentes cujo interesse principal se centra no valor de troca desses mesmos ecossistemas (o governo central e os promotores privados). Enquanto os primeiros tendem a exercer pressão sobre os segundos para reconhecer a necessidade de tomar decisões que visem a minimização dos impactes ambientais socialmente percepcionados como negativos ao nível local, o Estado e os promotores privados raramente concretizam essas medidas, embora possam dar respostas positivas às queixas e aos protestos populares. Estas respostas, tal

\footnotetext{
${ }^{23} \mathrm{Na}$ realidade, apenas pudemos apurar as respostas obtidas em $40 \%$ dos casos.

${ }^{24}$ Este aspecto é também diverso dos resultados obtidos na Espanha e na Grécia para o mesmo tipo de agentes, necessitando de uma maior investigação.
} 
como é referido por Gould (1991), são frequentemente materializadas em soluções que envolvam o mínimo de custos possível e usualmente de tipo não tecnológico.

\section{Conclusão}

A análise que acabámos de realizar revela uma tendência para o aumento de casos de protesto popular na área do ambiente em Portugal. O aumento destes movimentos de base popular relaciona-se de perto com as transformações ocorridas no contexto social, económico e político do país ao longo das últimas décadas. Salientámos que, após 1974, não apenas os problemas ambientais se agravaram, fruto do maior desenvolvimento económico do país, como aumentou a oportunidade e a capacidade interventora da sociedade civil em muitos domínios.

Os dados apresentados sugerem o forte carácter Nimby dos protestos populares no domínio do ambiente, inscrevendo assim estes movimentos de protesto no contexto mais alargado das características da sociedade portuguesa em geral face às questões ambientais. O carácter Nimby dos protestos populares é revelado pelo seu localismo que não é apenas geográfico, mas é sobretudo evidenciado pelo tipo de preocupações manifestadas, centradas na defesa dos interesses locais. Fomos salientando que esta é, aliás, uma característica partilhada com os movimentos de base popular de outros países ocidentais onde foram conduzidas investigações nesta matéria. Os casos analisados para o nosso país assemelham-se ainda aos observados noutros contextos pela ênfase dada à necessidade de informação sobre os projectos/actividades em causa, pela exigência de um maior envolvimento da população local nas decisões tomadas, pela ambivalência das atitudes face aos técnicos e cientistas, pela desconfiança nas autoridades políticas e ainda pelo tipo de actores e agentes desafiados e a que se recorre ao longo dos protestos (Freundenberg e Steinsapir, 1992; Fidélis et al., 1996; Kousis, 1999a e 1999b; Figueiredo et al., 2001).

Verificámos que o Estado (nos seus vários níveis) é o organismo a que com maior frequência se recorre durante os protestos. É igualmente o Estado (em conjunto com os promotores privados) o organismo mais vezes desafiado pelos participantes nos movimentos ambientais de base popular. Este aparente paradoxo evidencia as diversas funções que o Estado assume nas sociedades contemporâneas, sendo ao mesmo tempo representado como causador e solucionador dos conflitos. Como vimos, num e noutro caso, as respostas estatais tendem para uma certa neutralidade. Mesmo que a resposta dada seja positiva, as soluções propostas são pouco eficazes ou não materializadas. 
Por outro lado, fomos referindo ao longo do trabalho que os movimentos de raiz popular em Portugal se diferenciam dos analisados em outros países, designadamente pela sua natureza marcadamente rural e pelo carácter pouco violento e radical das acções desenvolvidas ao longo dos processos de protesto. Como dissemos antes, particularmente quanto ao primeiro aspecto, são necessárias mais investigação e análise empírica no sentido de aprofundar as causas desta característica. Outros resultados discutidos neste trabalho necessitam de posterior aprofundamento e relacionação, quer entre si, quer com outros aspectos da sociedade portuguesa, designadamente a articulação dos movimentos ambientais de base popular com movimentos também de raiz popular em outros domínios, de forma a poder medir e avaliar o peso das questões ambientais como potenciadoras deste tipo de movimentos. Por outro lado, devido sobretudo à indisponibilidade de dados, profundamente associada ao tipo de abordagem metodológica utilizada - a análise documental das notícias publicadas em dois jornais - não nos foi possível avaliar inteiramente o modo como o Estado responde a estes protestos populares. Seria necessária uma investigação mais cuidada acerca da relação entre as causas dos protestos, o tipo de propostas para a solução dos conflitos e as soluções alcançadas de facto, tendo em conta o papel do Estado nesses processos. A composição interna destes grupos de protesto é também um aspecto que merece maior investigação, já que, na maioria dos casos, o peso de determinadas categorias sociais (por exemplo as mulheres, determinados grupos socioprofissionais, etc.) não é visível através da análise dos artigos publicados na imprensa. Este peso torna-se mais importante quando os casos de protesto são analisados a partir de uma abordagem metodológica mais próxima da realidade em análise, compreendendo, por exemplo, entrevistas em profundidade aos dirigentes dos movimentos, aos actores sociais locais envolvidos e às entidades políticas e económicas abordadas.

\section{Referências Bibliográficas}

CCE (1986), Europeans and the Environment in 1986. Bruxelas.

CCE (1988), Europeans and the Environment in 1988. Bruxelas.

CCE (1992), Europeans and the Environment in 1992. Bruxelas (Eurobaromètre 37.0).

CCE (1995), Europeans and the Environment in 1995. Bruxelas (Eurobaromètre 37.0).

CCE (1999), What do Europeans Think about the Environment?. Luxembourg: Office for Official Publications of the European Communities.

Cable, Sherry; Cable, Charles (1995), Environmental Problems, Grassroots Solutions: The Politics of Grassroots Environmental Conflicts. New York: St. Martin's Press. 
Dunlap, Riley E. (1996), “A Sociological Perspective on Environmental Problems”, in Carlos Borrego et al. (orgs.), Actas da V Conferência Nacional sobre a Qualidade do Ambiente. Aveiro: DAO/CCRC, 99-120.

Dunlap, Riley E. et al. (1994), "International Attitudes towards Environment and Development”, in H. O. Bergesen et al. (orgs.), Green Globe Yearbook of International Co-Operation on Environment and Development. Oxford: Oxford UP, 115-126.

Dunlap, Riley E. et al. (1995), "Global Environmental Concern: A Challenge to the Post-Materialism Thesis”, comunicação apresentada na Conferência O Ambiente como Preocupação Global, Lisboa, FLAD.

Eloy, António (1994), "O ambiente e o ordenamento do território", in António Reis (org.), Portugal, vinte anos de democracia. Lisboa: Círculo de Leitores, 331-345.

Fidélis, Teresa et al. (1996), "Grassroots Environmental Action in Portugal - A Case Study on a Landfill Sitting”, comunicação apresentada à Euro-conference Environment and Innovation, Viena.

Figueiredo, Elisabete; Martins, Filomena (1996a), "Pensar Verde - contributos para o estudo da formação de uma consciência ambiental em Portugal”, in ICS/UL (org.), Dinâmicas multiculturais, novas faces, outros olhares. Lisboa: ICS, 417-436.

Figueiredo, Elisabete; Martins, Filomena (1996b), "O ambiente no discurso político em Portugal (1976-1995) - algumas reflexões”, Vértice, 76, 55-66.

Figueiredo, Elisabete; Martins, Filomena (1999), "O cidadão na construção de um ambiente melhor", comunicação apresentada ao Seminário sobre Higiene Ambiental, Coimbra: HUC.

Figueiredo, Elisabete; Fidélis, Teresa (2000), "No meu quintal não! Análise dos movimentos ambientais de raiz popular em Portugal", in APS (org.), Sociedade portuguesa, passados recentes, futuros próximos - Actas do IV Congresso Português de Sociologia. Lisboa: APS (CD-ROM).

Figueiredo, Elisabete et al. (2001), “Grassroots Environmental Action in Portugal (1974-1994)”, in K. Eder; M. Kousis (orgs.), Environmental Politics in Southern Europe Actors, Institutions and Discourses in a Europeanizing Society. Dordrecht: Kluwer Academic Publishers, 197-224.

Freudenberg, N.; Steinsapir, C. (1992), "Not in Our Backyards - The Grassroots Environmental Movement”, in R. E. Dunlap; A. Mertig (orgs.), American Environmentalism. Washington: Taylor \& Francis, 27-35.

Freundenburg, William R.; Pastor, Susan K. (1992), "Nimby's and Lulu's: Stalking the Syndromes”, Social Issues, 48(4), 39-61.

Garcia, José Luis et al. (2000), "Orientação, cidadania e responsabilização", in João Ferreira de Almeida (org.), Os Portugueses e o Ambiente - I inquérito nacional às representações e práticas dos Portugueses sobre Ambiente. Oeiras: Celta, 145-184. Inglehart, Ronald (1990), Culture Shift in Advanced Industrial Society. Princeton: Princeton UP. 
Inglehart, Ronald (1997), Modernization and Post-Modernization - Cultural, Economic and Political Change in 43 Societies. Princeton: Princeton UP.

Kousis, Maria (1999a), "Sustaining Local Environmental Mobilizations: Groups, Actions and Claims in Southern Europe”, Environmental Politics (Special Issue on Environmental Movements), 8(1), 172-198.

Kousis, Maria (1999b), "Environmental Protest Cases: The City, the Countryside and the Grassroots in Southern Europe", Mobilization, 4(2).

Kousis, Maria (2001), "Competing Claims in Local Environmental Conflicts in Southern Europe”, in K. Eder; M. Kousis (orgs.), Environmental Politics in Southern EuropeActors, Institutions and Discourses in a Europeanizing Society. Dordrecht: Kluwer Academic Publishers, 129-150.

Kousis, Maria et al. (1996), Final Report: Grassroots Environmental Action and Sustainable Development in Southern European Union, European Commission, DGXII, contract n. ${ }^{\circ}$ EV5V-CT94-0393.

Lowe, P.; Goyder, J. (1983), Environmental Groups in Politics. London: Allen \& Unwin. Mansinho, Inês; Schmidt, Luísa (1994), “A emergência do ambiente nas Ciências Sociais”, Análise Social, 39(127), 441-481.

MARN (1995), Plano Nacional de Política de Ambiente. Lisboa: Ministério do Ambiente e Recursos Naturais.

Marques, Viriato Soromenho (1994), Regressar à terra - Consciência ecológica e política do ambiente. Lisboa: Fim de Século.

Melo, João Joanaz de; Pimenta, Carlos (1993), Ecologia e ambiente. Lisboa: Difusão Cultural.

Mormont, Marc (1993), Sciences Sociales et environnement - Approches et conceptualisations. Arlon: FUL

Nave, Joaquim Gil (2000), The Politics of Environmental Groups in Portugal. Florença: European University Institute (diss. de doutoramento).

Nave, Joaquim Gil (2001), "Non-Governmental Groups and the State”, in K. Eder; M. Kousis (orgs.), Environmental Politics in Southern Europe - Actors, Institutions and Discourses in a Europeanizing Society. Dordrecht: Kluwer Academic Publishers, 343-364.

Nave, Joaquim Gil; Fonseca, Susana (2000), “Acção colectiva e participação na área do ambiente: fenomenologia e mobilização de recursos das organizações não-governamentais do ambiente", in APS (org.), Sociedade portuguesa, passados recentes, futuros próximos - Actas do IV Congresso Português de Sociologia. Lisboa: APS (CD-ROM).

Pureza, José Manuel (1997), Tribunais, natureza e sociedade. Lisboa: Centro de Estudos Judiciários.

Reis, António (1994), "O processo de democratização”, in António Reis (org.), Portugal, vinte anos de democracia. Lisboa: Círculo de Leitores, 19-39. 
Reis, Manuela; Lima, Aida Valadas (1998), "Desenvolvimento, território e ambiente", in J. M. Viegas; A. F. Costa (org.), Portugal: Que modernidade?. Oeiras: Celta, 329-363.

Rodrigues, Eugénia (1995), "Os novos movimentos sociais e o associativismo ambientalista em Portugal”, Oficina do CES, 60.

Santos, Boaventura de Sousa (1990), O Estado e a sociedade em Portugal (1974-1988). Porto: Afrontamento.

Schmidt, Luísa et al. (2000), "País, percepção, retrato e desejo", in João Ferreira de Almeida (org.), Os Portugueses e o Ambiente - I Inquérito nacional às representações e práticas dos Portugueses sobre Ambiente. Oeiras: Celta, 33-101.

Schnaiberg, A. (1992), “The Hazards of Production: How Do Communities React?", Science, 255, 1586-1587.

Taylor, B. R. (1995), Ecological Resistance Movements: The Global Emergence of Radical and Popular Environmentalism. Albany, NY: Suny Press.

Yearley, Steven (1992), A causa verde: Uma sociologia das questões ecológicas. Oeiras: Celta. 